\title{
Comparison of triggering systems for neonatal patient triggered ventilation
}

\author{
M F Hird, A Greenough
}

\begin{abstract}
The efficacy of two triggering systems was compared during neonatal patient triggered ventilation: the Graseby MR10 respiration monitor and airway pressure changes. Ten preterm infants were studied, median gestational age 33 weeks (range 28-35). Patient triggered ventilation was administered via the SLE ventilator at a series of inflation times ( $0.24,0.3$, and 0.4 seconds). Comparison was made between the trigger systems of the trigger delay, inflation volume delivered, and proportion of spontaneous respiratory efforts detected. The airway pressure trigger gave a superior performance: at the two lower inflation times the trigger delay was shorter and inflation volume delivered greater. At the longest inflation time a greater proportion of respiratory efforts were detected. We concude the airway pressure trigger should be used in preference to the respiration monitor as the triggering system of choice for neonatal patient triggered ventilation.
\end{abstract}

Patient triggered ventilation has now been available for neonatal use for about three years. ${ }^{1}$ The commercially available system incorporates as a trigger system a Graseby MR10 respiration monitor. The Graseby capsule detects the infant's respiratory efforts by changes in abdominal expansion and is commonly used for the detection of central apnoea. The signal from this capsule can be used to trigger the manual breath control of the SLE ventilator. The ventilator so triggered delivers a single positive pressure inflation of magnitude and duration previously determined in conventional mode. Using this system one centre has demonstrated, in a small number of infants, improved gas exchange when compared with conventional ventilation. ${ }^{1}$ They have also claimed that patient triggered ventilation is associated with a lower incidence of pneumothorax, ${ }^{2}$ but only made comparison with historical controls. Although this triggering system is now commercially available, it remains in limited supply and no other centres have reported on the efficacy of this system.

We have also had experience of patient triggered ventilation and reported similar short term benefits - that is, improvements in blood gases. ${ }^{34}$ These results, however, were obtained using a variety of other triggering mechanisms: changes in oesophageal pressure or airflow. ${ }^{34}$ Oesophageal pressure changes provide an effective trigger system in the short term, but the sensitivity gradually declines with the build up of secretions and oesophageal peristalsis may modify the signal. ${ }^{3}$ Airflow changes are detected by means of a pneumotachograph inserted into the circuit, but this has to be removed for suctioning of the airway and may add critically to the dead space of the circuit. ${ }^{4}$ Monitoring airway pressure changes is another possible triggering mechanism and this can be performed by addition of a small $\mathrm{T}$ piece into the circuit, just proximal to the endotracheal tube. This system we have found easy to use and has none of the disadvantages of the previous two triggering mechanisms we have tested.

The aim of this study was to compare the efficacy of this airway pressure trigger with the commercially available triggering system-that is, the Graseby MR10 respiration monitor.

\section{Patients and methods}

Ten preterm infants were studied. All were ventilated for respiratory distress with a median (range) gestational age of 33 (28-35) weeks and median (range) birth weight of 1725 (970-2692) $g$ using the SLE ventilator. Their median (range) postnatal age was 33 (10-300) hours; only one infant was more than 96 hours of age.

Ethical permission for this study was given by the King's College ethics committee.

Patients were entered into the study and changed from conventional ventilation to patient triggered ventilation. They were allocated to receive in random order one of the two triggering systems. The triggering systems involved monitoring either changes in abdominal expansion via the Graseby capsule ${ }^{1}$ or airway pressure changes. To monitor changes in abdominal expansion, the pneumatic capsule of the Graseby MR10 respiration monitor was taped onto the patient's abdominal wall in the subxiphisternal position with adhesive tape extending from the abdominal wall above the umbilicus, across the capsule to the skin overlying the xiphisternum and then connected to the monitor. This site of placement was chosen as it had been reported to be the site that most reliably detects respiratory efforts and is least affected by abdominal movement not due to respiratory activity. ${ }^{5}$ We also found we could detect the maximum proportion of spontaneous breaths at the subxiphisternal position in comparison to other sites. The output from the capsule then triggered the manual breath control of the SLE ventilator. The signal from the monitor, which recorded changes in capsular volume, was also displayed on a paper record. To monitor airway pressure changes a $T$ piece was inserted into the circuit, just proximal to 
the endotracheal tube, this was then connected to the ventilator by non-compliant tubing. An airway pressure change of greater than $0.5 \mathrm{~cm}$ $\mathrm{H}_{2} \mathrm{O}$ was necessary to trigger the ventilator. This permits detection of the fall in airway pressure at the $T$ piece which represents the initiation of spontaneous inspiratory effort by an infant.

Using each trigger system the infants were ventilated at a series of inflation times, 0.24 , 0.3 , and 0.4 seconds, for 10 minute periods returning between each period to conventional ventilation at the ventilator rate in use before patient triggered ventilation. These inflation times were chosen to equal approximately the expected spontaneous inspiratory time for infants breathing at rates of 60,80 , and 100 breaths per minute, making allowance for the systems delay of up to $\mathbf{4 0}$ msecs. ${ }^{6}$ No change was made in peak pressure, positive end expiratory pressure, or gas flow rates throughout the study.

During patient triggered ventilation simultaneous recordings were made of flow, volume, ventilator, and oesophageal pressure changes ${ }^{3}$ and the output from the Graseby capsule. ${ }^{5}$ From the recordings the inflation volume and trigger delay were calculated. At each new inflation time the infant was allowed to settle for the first five minutes. Inflation volume was then calculated as the mean of the inflation volume over the final five minute period at each inflation time. The trigger delay was calculated as the time lag from the start of inspiration, indicated by a negative deflection in the oesophageal pressure trace, and the onset of ventilator breath. The trigger delay was also expressed as a mean of the delays over the last five minutes. The number of spontaneous breaths detected and thus triggering the ventilator were also calculated. This was determined by counting, over the last five minutes of the trace, the number of inspiratory efforts recorded by oesophageal pressure changes, and the number of ventilator inflations. The result was then expressed as a percentage, that is, the number of inflations divided by the number of spontaneous inspirations.

Differences between the two systems at each inflation time were assessed for significance using a paired Wilcoxon rank sum test.

\section{Results}

The inflation volume at both 0.24 and 0.3 seconds was significantly larger using the airway pressure compared with the Graseby system (table 1). Lengthening the inspiratory time was associated with an increase in the trigger delay for both systems; however, the trigger delay was

Table 1 Inflation volume and trigger delay at different inflation times. Results are median (range)

\begin{tabular}{|c|c|c|c|c|}
\hline \multirow{2}{*}{$\begin{array}{l}\text { Inflation } \\
\text { time } \\
\text { (seconds) }\end{array}$} & \multicolumn{2}{|c|}{ Inflation volume $(\mathrm{ml} / \mathrm{kg})$} & \multicolumn{2}{|c|}{ Trigger delay (ms) } \\
\hline & $\begin{array}{l}\text { Airway } \\
\text { pressure }\end{array}$ & $\begin{array}{l}\text { Graseby MR10 } \\
\text { respiration } \\
\text { monitor }\end{array}$ & $\begin{array}{l}\text { Airway } \\
\text { pressure }\end{array}$ & $\begin{array}{l}\text { Graseby MRIO } \\
\text { respiration } \\
\text { monitor }\end{array}$ \\
\hline $\begin{array}{l}0 \cdot 24 \\
(n=10) \\
0 \cdot 3 \\
(n=10) \\
0 \cdot 4 \\
(n=8)\end{array}$ & $\begin{array}{l}5 \cdot 8 \\
(3 \cdot 5-10 \cdot 3) \\
6 \cdot 30 \\
(3 \cdot 3-11 \cdot 3) \\
6 \cdot 25 \\
(3 \cdot 1-10 \cdot 8)\end{array}$ & $\begin{array}{l}4 \cdot 6^{*} \\
(1 \cdot 7-8 \cdot 4) \\
5 \cdot 4^{*} \\
(2 \cdot 0-9 \cdot 2) \\
4 \cdot 9^{*} \\
(2 \cdot 8-8 \cdot 8)\end{array}$ & $\begin{array}{l}200 \\
(50-400) \\
200 \\
(40-300) \\
250 \\
(40-550)\end{array}$ & $\begin{array}{l}300^{*} \\
(100-600) \\
350^{*} \\
(100-800) \\
550 \\
(100-600)\end{array}$ \\
\hline
\end{tabular}

Because of increased asynchronous effects accurate measurements could only be made in eight of 10 infants at inflation time of 0.4 seconds. 0.4 secon
${ }^{\mathrm{p}}<0.05$.

Volume

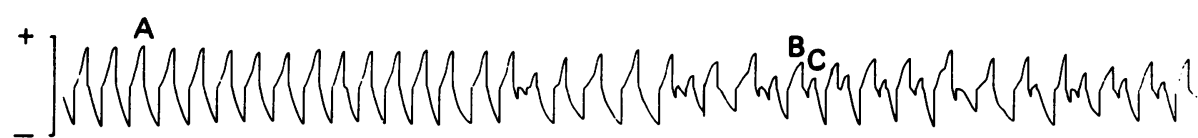

Ventilator

pressure

Peak inspiratory pressure

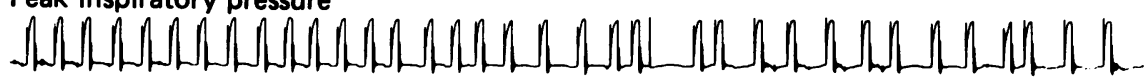

Positive end expiratory pressure

Expiration

Oesophageal

pressure

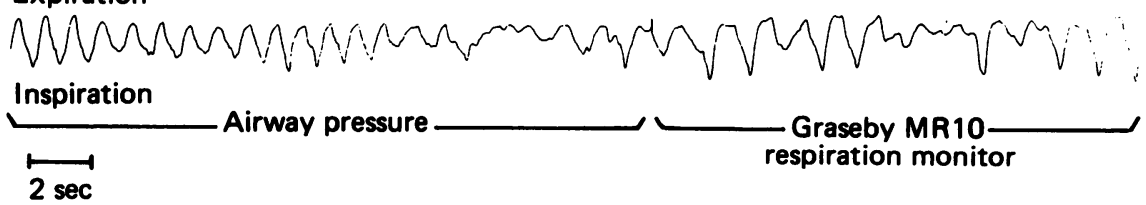

Respiratory recording showing the effect of changing from the airway pressure to the Graseby capsule trigger system. Volume is represented in the upper trace (inspiration upwards), ventilator pressure the middle trace, and oesophageal pressure the bottom trace, inspiration represented by a downwards deflation. The inflation time is 0.24 seconds; peak inspiratory pressure and flow trace, inspiration represented by a down

Using the airway pressure triggering system, ventilator inflation is coincident with inspiration and is complete by the onset of spontaneous expiration $(A)$. On changing to the Graseby capsule MRIO triggering system, the ventilator breath is freguently delivered at the end of spontaneous expiration because of the prolonged trigger delay, spontaneous inspiration $(B)$ results in a langer tidal volume than positive pressure inflation $(C)$, both display a smaller tidal volume than that seen with the airway pressure trigger system. 
Table 2 Association of spontaneous breaths to triggered ventilator. Results are median (range)

\begin{tabular}{llll}
\hline $\begin{array}{l}\text { Inflation } \\
\text { time } \\
\text { (seconds) }\end{array}$ & $\begin{array}{l}\text { Spontaneous } \\
\text { respiratory } \\
\text { rate (beats/min) }\end{array}$ & $\begin{array}{l}\text { Ventilator rate } \\
\text { (\% of spontaneous } \\
\text { inspiratory rate) }\end{array}$ \\
\cline { 3 - 4 } & & $\begin{array}{l}\text { Airway } \\
\text { pressure }\end{array}$ & $\begin{array}{l}\text { Graseby } \\
\text { MRI0 } \\
\text { respiration } \\
\text { monitor }\end{array}$ \\
\hline $0 \cdot 24$ & 69 & 100 & 92 \\
$(\mathrm{n}=10)$ & $(48-132)$ & $(89-100)$ & $(50-100)$ \\
$0 \cdot 3$ & 69 & 100 & 89 \\
$(\mathrm{n}=10)$ & $(42-132)$ & $(87-100)$ & $(50-100)$ \\
$0 \cdot 4$ & 63 & $100^{*}$ & $73^{*}$ \\
$(\mathrm{n}=8)$ & $(36-120)$ & $(80-100)$ & $(62 \cdot 5-100)$ \\
\hline
\end{tabular}

${ }^{*} \mathrm{p}<0.05$.

always longer using the Graseby capsule (table 1). The prolonged trigger delay using the Graseby capsule often meant that inflation was delivered late in expiration resulting in a low inflation volume (figure). Using the airway pressure system, all spontaneous breaths were detected in the majority of infants. This, however, was not the case with the Graseby system where a proportion of spontaneous breaths were undetected (table 2). Throughout the study the inspired oxygen concentration was increased if either the transcutaneous oxygen or arterial oxygen tension $\left(\mathrm{PaO}_{2}\right)$ fell below 6.67 $\mathrm{kPa}$. This was necessary in three infants using the Graseby trigger but in none using the airway pressure trigger.

\section{Discussion}

These results show that the airway pressure device is superior to the Graseby capsule in detecting respiratory efforts. Monitoring of spontaneous respiration using a pneumatic capsule requires considerable skill in placement. ${ }^{5}$ Ventilator inflation can cause abdominal excursion, although positioning of the capsule in the subxiphisternal position, as done in this study, reduces the interference from mechanical ventilation in detecting spontaneous respiration. ${ }^{5}$ Body movements as well as spontaneous respiratory efforts, however, can also cause changes in abdominal expansion and may, by interference, have resulted in the relatively low detection of respiratory efforts seen in this study. The results of a postal survey we undertook confirmed this finding, $41 \%$ of units surveyed complaining of difficulty in achieving optimum placement of the capsule and a relatively poor detection rate. The airway pressure trigger system, in contrast, is much simpler to use, as a T tube is easily placed between the ventilator circuit and endotracheal tube. Its other major advantage is that it does not detect gross movement artefact. The system also appears more sensitive, with virtually every inspiratory effort triggering a positive pressure inflation.

The Graseby system was associated with a significantly longer trigger delay at all inflation times. A long trigger delay has a number of disadvantages. A lag in the onset of the positive pressure inflation will result either in most of the spontaneous inspiration being unsupported by ventilator inflation or in some cases ventilator inflation occurring only after completion of spontaneous inspiration. Such interactions result in diminished inflation volumes compared with those seen when the trigger delay is short, this will reduce minute volume and hence may impair gas exchange. A long trigger delay also means that unless extremely short inflation times are used, with possible deleterious effects on the waveform, ${ }^{7}$ positive pressure inflation could extend into spontaneous expiration, provoking an asynchronous interaction and hence increasing airleaks. ${ }^{8}$ No infant in this study developed a pneumothorax and short inflation times (maximum 0.4 seconds) were used throughout, but the sample size was too small to make a meaningful statement regarding the influence of patient triggered ventilation on the incidence of airleak.

Although the airway pressure trigger system was superior to the system utilising the Graseby MR10 capsule, even the airway pressure trigger delay may be too long. This delay could be reduced by decreasing the gas flow within the circuit. Such a reduction would diminish the amount of effort the infant would have to generate to exceed the continuous pressure within the circuit and thus exceed the pressure necessary to trigger the ventilator. Reduction in flow would, however, adversely affect ventilator waveform, particularly if short inflation times were being used. ${ }^{7}$ We conclude other triggering systems and forms of patient triggered ventilation need to be urgently evaluated. In the meanwhile, we recommend that the airway pressure trigger should be used for neonatal patient triggered ventilation in preference to the Graseby MR10 respiration monitor.

Dr M Hird (research fellow) is supported by Children NationDr $M$ Hird (research fellow) is supported by Children Nationwide. The equipment used in this study was generously provided by Children

1 Mehta A, Callan K, Wright BM, Stacey TE. Patient triggered ventilation in the newborn. Lancet 1986;ii:706-12.

2 Clifford RD, Whincup G, Thomas R. Patient triggered ventilation prevents pneumothoraces in premature babies. Lancet 1988; i:529-30.

3 Greenough A, Greenall F. Patient triggered ventilation in premature neonates. Arch Dis Child 1988;63:77-8.

4 Greenough A, Pool J. Neonatal patient triggered ventilation. Arch Dis Child 1988;63:394-7.

5 South M, Morley CJ. A technique for monitoring spontaneous respiration in the ventilated neonate. Arch $D$ is Child 1986;61:291-4.

6 Mitchell A, Greenough A, Hird MF. Limitations of neonatal patient triggered ventilation. Arch Dis Child 1989;64: 924-9.

7 Greenough A, Greenall F. Performance of respirators at fast rates commonly used in neonatal intensive care units. rates commoniy used in neonatal

8 Greenough A, Morley CJ, Davis JA. The interaction of the infants' spontaneous respiration and artificial ventilation. f Pediatr 1983;103:769-73. 